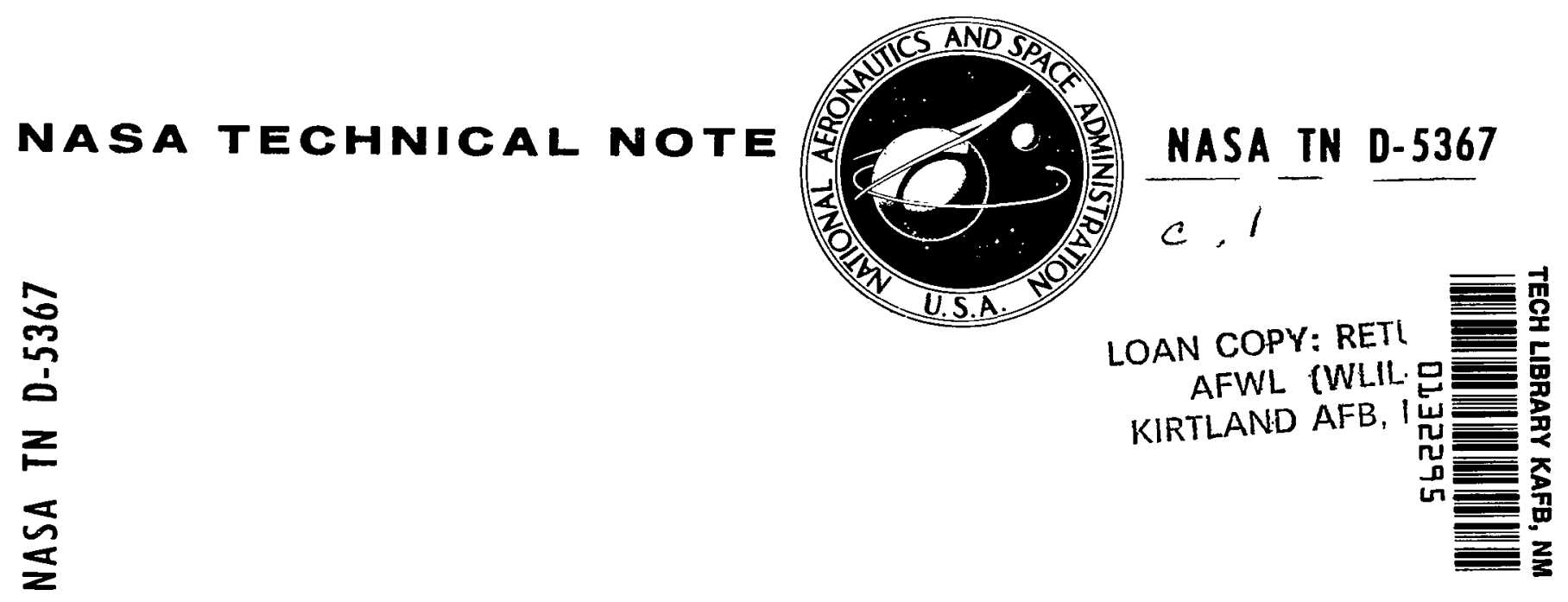

\title{
FAILURE CRITERIA FOR FILAMENTARY COMPOSITES
}

by Christos C. Chamis

Lewis Research Center

Cleveland, Obio

National aeronaUtics and SPACE administration - WASHINGTON, D. C. - aUgUSt 1969 
FAILURE CRITERIA FOR FILAMENTARY COMPOSITES

By Christos C. Chamis

Lewis Research Center

Cleveland, Ohio

\section{NATIONAL AERONAUTICS AND SPACE ADMINISTRATION}

For sale by the Clearinghouse for Federal Scientific and Technical Information Springfield, Virginia 22151 - CFSTI price $\$ 3.00$ 


\section{ABSTRACT}

A two-level, linear, semiempirical theory for a failure criterion is described. The theory predicts the strength behavior of unidirectional filamentary composites under uniaxial and combined stress from basic constituent material properties and fabrication process considerations. Applications of the theory to several filament-nonmetallic matrix composites are presented and comparisons are made with experimental data. These results show good agreement between theory and experiment. Simple and combined strength envelopes are generated to illustrate the versatility of the theory and to point out problem areas in experimental work and design. 


\section{FAILURE CRITERIA FOR FILAMENTARY COMPOSITES* \\ by Christos $\mathrm{C}$. Chamis \\ Lewis Research Center}

\section{SUMMARY}

Failure criteria in the form of a two-level, linear, semiempirical theory to predict the strength behavior of unidirectional filamentary composites are presented. The first-level theory predicts the uniaxial strengths of the composite from its constituent material properties and fabrication process considerations. The second-level theory describes the strength behavior of the composite from its uniaxial (simple) strengths. The first-level theory is based on a modified rule of mixtures relation, on matrix-strainmagnification factors, and on maximum void effects. It considers both filaments and matrix as being generally orthotropic and reflects the particular fabrication process through the judicious incorporation of certain empirical factors. The second-level theory (combined-stress strength criterion) is based on a modified distortion energy principle. It is expressed as an interaction equation with a coefficient depending on the composite's elastic properties. This coefficient is to be modified for theory-experiment correlation. The criterion is applicable to materials exhibiting different magnitudes in tensile and compressive strengths as well as to isotropic materials.

The physical bases and the mathematical formalisms leading to the two-level theory are described. Suggested experimental techniques to measure the simple strengths and to evaluate the correlation coefficients (empirical factors) are illustrated. The need for controlled experimental data and complete test records is emphasized. Application of the two-level theory to several multilayered filament-matrix composites is presented to illustrate its application and to compare it with experimental data. These results indicate that the two-level theory predicts the composite strength behavior reasonably well. Composite simple and combined strength envelopes are generated to illustrate the versatility of the theory and to point out problem areas in experimental work and design.

* A portion of this work was supported by the Advanced Research Projects Agency, Department of Defense, through Grant no. AF 33(615)-3110, administrated by the Air Force Materials Laboratory while the author was a member of the Engineering Design Center, Case Western Reserve University, Cleveland, Ohio. 


\section{INTRODUCTION}

Experimental observations have shown that unidirectional fiber composites exhibit five primary failure stresses, also referred to as limit stresses and simple strengths. These stresses result when the composites are subjected to failure under uniaxial loading in their plane. The failure stresses are identified individually as follows: (1) longitudinal tensile $\left(\mathrm{S}_{l 11 \mathrm{~T}}\right)$, (2) longitudinal compressive $\left(\mathrm{S}_{l 11 \mathrm{C}}\right)$, (3) transverse tensile $\left(\mathrm{S}_{l 22 \mathrm{~T}}\right)$, (4) transverse compressive $\left(\mathrm{S}_{222 \mathrm{C}}\right)$, and (5) intralaminar (inplane) shear $\left(\mathrm{S}_{212 \mathrm{~S}}\right)$. These stresses are illustrated in figure 1. (See also ref. 1, ch. 2.) Experimental observations

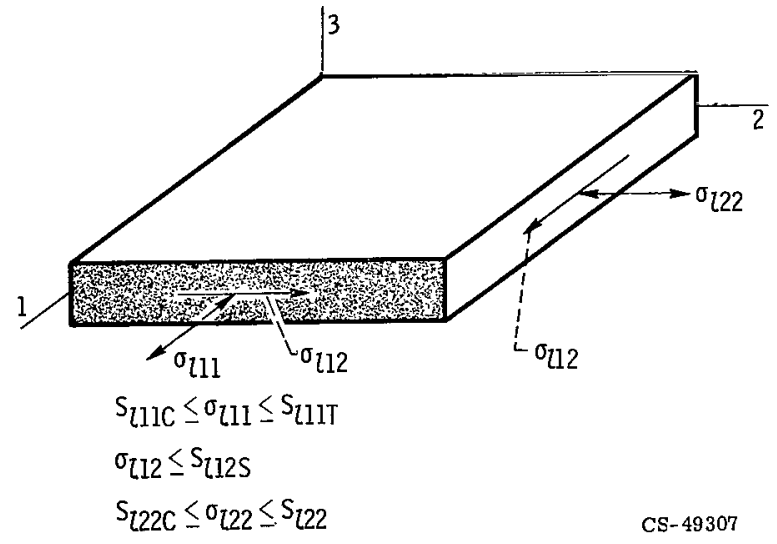

Figure 1. - Unidirectional filamentary composite (geometry and simple strength definitions).

also show that unidirectional fiber composites under combined loading fail at stress considerably different from those under simple loading (ref. 1, ch. 3). Therefore, five simple strengths and a combined-stress strength criterion are needed to describe the strength (limit) behavior of a unidirectional filamentary composite (UFC). Three alternatives are possible in determining the simple strengths and the combined-stress strength criterion: (1) empirical, (2) theoretical, and (3) semiempirical.

The empirical approach evaluates the simple strengths and the combined-stress strength criterion by measurement of specific filament-matrix systems. This approach, though effective if only one system is considered, is economically prohibitive when feasibility and trade -off studies are needed in considering several filament-matrix systems with a range of filament volume content for each system. The case for combined loading is far more complex. This requires complex experimental setups and many experiments to establish a reasonable failure criterion for a given load envelope.

The theoretical approach is based on some mathematical model of the physical makeup of a UFC. Examination of its physical makeup reveals that its strength depends 
on the properties of its constituents and the particular fabrication process. What is needed, then, is a mathematical formalism to relate the strength of the UFC to the properties of its constituents and to the particular fabrication process. This mathematical formalism can be constructed with the aid of a two-level theory. The first level is a theory to predict the simple strengths of the UFC from constituent properties and fabrication process considerations. The second level is a theory to predict the onset of failure (limiting condition) of the UFC from either the simple strengths (predicted in the first level) or from certain measured values. The failure criteria at both levels, to be effective and useful for design practice, must account directly or indirectly for the following desirable features:

(1) They must have some theoretical basis.

(2) They should reflect the particular fabrication process (void content, size, and distribution; filament spacing nonuniformities and misalinement; differences in bulk and in-situ constituent properties; imperfect interface bond; residual stress, etc.).

(3) They must be applicable to both isotropic and anisotropic filaments and matrices.

(4) The resulting equations should be relatively simple.

(5) The theories must be experimentally substantiated at both levels.

Various theories have been proposed in the literature. Representative first-level theories include: rule of mixtures (filament strength limited), netting analysis (ref. 2), and statistical (refs. 3 and 4$)$ for longitudinal tensile strength $\left(\mathrm{s}_{211 \mathrm{~T}}\right)$; rule of mixtures (matrix strength limited) (ref. 5), filament microbuckling (ref. 6), panel buckling (ref. 7), and constituent debonding with intralaminar shear (ref. 8) for longitudinal compressive strength $\left(\mathrm{S}_{211 \mathrm{C}}\right)$; and matrix stress concentration factors (refs. 9 and 10) and matrix strain magnification factors (refs. 11 and 12) for transverse tensile $\left(\mathrm{S}_{222 \mathrm{~T}}\right)$, transverse compressive $\left(\mathrm{S}_{222 \mathrm{C}}\right)$, and intralaminar shear $\left(\mathrm{S}_{212 \mathrm{~S}}\right)$ strengths. Representative second-level theories include: statistical (ref. 13), curve-fit quadratic (refs. 14 to 16), special ellipsoids (refs. 16 and 17), distortion energy (refs. 18 and 19), maximum strain (ref. 20, combinations (ref. 21), and fracture mechanics (ref. 22). Many of these theories are extensively discussed in chapters 2 and 3 of reference 1 and chapter 3 of reference 16. Here, suffice it to say that all these theories are deficient in either one or more of the desirable features delineated previously.

The semiempirical approach has not been explored to its fullest extent. In this report a two-level, semiempirical theory is described which meets (directly or indirectly) all the desirable features delineated previously. The theory at both levels is linear and developed primarily for nonmetallic composites. The basic hypothesis of this approach is that variables which cannot be accounted for directly are incorporated indirectly through the judicious introduction of theory-experiment correlation factors. The physical bases and justifications for these factors are discussed in this report. 


\section{SYMBOLS}

A array arrangement, distribution

$\overline{\mathrm{A}} \quad$ parameter, eq. (A9)

$a_{1}, a_{2}$ constants, eq. (4)

d diameter

E longitudinal modulus

F failure function

G shear modulus

$\mathrm{K}, \mathrm{K}^{\prime}$ elastic and correlation coefficients, respectively, eq. (12)

$\mathrm{k}, \overline{\mathrm{k}} \quad$ apparent and actual volume ratio, respectively

$\mathrm{N}$ number of filaments or voids

$\mathrm{N}_{\mathrm{x}}, \mathrm{N}_{\mathrm{y}}$ applied loads

p parameter, eq. (9)

S simple strength, failure or limit stress

t thickness

$\beta \quad$ theory-experiment correlation factor

$\epsilon \quad$ strain

$\theta \quad$ angle between load and filament directions

$\nu \quad$ Poisson's ratio

$\sigma \quad$ stress

$\varphi_{\mu} \quad$ strain-magnification factor

Subscripts:

B interface bonding

C compression

D debonding

f filament property

$l \quad$ ply property

m matrix property

p limiting property 


$\begin{array}{ll}\mathbf{R} & \text { residual stress } \\ \mathrm{S} & \text { shear } \\ \mathrm{T} & \text { tension } \\ \mathrm{v} & \text { void } \\ \mathrm{x}, \mathrm{y}, \mathrm{z} & \text { load axes } \\ 1,2,3 & \text { material axes (the } 1 \text {-axis coincides with the filament direction) } \\ \alpha, \beta & \mathrm{T} \text { or } \mathrm{C} \text { tension or compression }\end{array}$

\section{UNIAXIAL SIMPLE STRENGTHS}

The physical makeup of the UFC suggests that its simple strength will be related to its constituent properties and to the fabrication processes as follows:

$$
S_{\imath}=f\left[(k, d, N, A)_{f, v}, k_{m},\left(E, \nu, G, S, \epsilon_{p}\right)_{f, m}, s_{B}, S_{R}\right]
$$

where $S_{l}$ in equation (1) denotes the UFC simple strength; $(k, d, N, A)_{f, v}$ denotes volume content, size, number, and distribution of filaments and voids; $\mathrm{k}_{\mathrm{m}}$ denotes the volume content of the matrix; $\left(\mathrm{E}, \nu, \mathrm{G}, \mathrm{S}, \epsilon_{\mathrm{p}}\right)_{\mathrm{f}, \mathrm{m}}$ represents the elastic and strength properties of the filaments and matrix; and $\mathrm{S}_{\mathrm{B}}$ and $\mathrm{S}_{\mathrm{R}}$ denote interface bond strength and residual stress, respectively. The void content, the bond strength, and the residual stresses are dependent on the filament surface treatment. They also depend on various matrix additives, hardeners, temperature, and pressure during fabrication and on the fabrication method of making the UFC. As can be seen, the list of variables on which the UFC simple strengths depend is quite long.

Evaluation of the function in equation (1) presents a formidable task which requires sophisticated statistical methods and a large number of experiments. This results in complex mathematical expressions not readily amenable to use in design. Variables such as void size and distribution, filament spacing nonuniformity, interface bond strength, and residual stresses are influenced by the particular fabrication process. If it is assumed that the particular fabrication process remains approximately invariant, then it is reasonable to group all these variables into theory-experiment correlation factors. The concept just stated simplifies the derivations and resulting expressions of the simple strengths and yet retains all the essential parts of equation (1). The details are described in the following sections. 


\section{Longitudinal Tensile Failure Stress $S_{\text {ll1T }}$}

The expression describing the longitudinal tensile strength is a modified rule of mixtures equation of the form

$$
\mathrm{S}_{\mathrm{i} 1 \mathrm{~T}}=\mathrm{S}_{\mathrm{fT}}\left[\beta_{\mathrm{fT}} \overline{\mathrm{k}}_{\mathrm{f}}+\beta_{\mathrm{mT}} \overline{\mathrm{k}}_{\mathrm{m}}\left(\frac{\mathrm{E}_{\mathrm{m} 11}}{\mathrm{E}_{\mathrm{f} 11}}\right)\right]
$$

where $S_{f T}$ is the filament bundle strength (or single filament strength for monofilament composites); $\beta_{\mathrm{fT}}$ and $\beta_{\mathrm{mT}}$ are the theory-experiment correlation factors, which account for the particular fabrication process; $\overline{\mathrm{k}}_{\mathrm{f}}$ and $\overline{\mathrm{k}}_{\mathrm{m}}$ are actual filament and matrix volume contents and are defined in the appendix; and $\mathrm{E}_{\mathrm{m} 11}$ and $\mathrm{E}_{\mathrm{f} 11}$ represent the insitu longitudinal moduli of the matrix and filament, respectively.

Several important points should be noted: (1) equation (2) is linear in $\bar{k}_{\mathrm{f}}$ if $\beta_{\mathrm{fT}}$ and $\beta_{\mathrm{mT}}$ are independent of $\overline{\mathrm{k}}_{\mathrm{f}}$. The filament bundle strength (single filament for monofilament composites) controls $\mathrm{S}_{211 \mathrm{~T}}$. (2) When $\left(\mathrm{E}_{\mathrm{m} 11} / \mathrm{E}_{\mathrm{f} 11}\right) \ll 1, \mathrm{~S}_{211 \mathrm{~T}}$ is insensitive to $\beta_{\mathrm{mT}}$. (This is the basic hypothesis in the netting analysis.) (3) The coefficients $\beta_{\mathrm{fT}}$ and $\beta_{\mathrm{mT}}$ should be relatively independent of the filament volume content for a fixed fabrication system. (4) The proximity to unity of these coefficients is a measure of the validity of the rule of mixtures and of the relative insensitivity of $\mathrm{S}_{211 \mathrm{~T}}$ to the fabrication process.

\section{Longitudinal Compressive Failure Stress $S_{\text {Z11C }}$}

Using the rule of mixtures, the longitudinal compressive strength is related to constituent properties by the following equation:

$$
\mathrm{S}_{211 \mathrm{C}}=\mathrm{S}_{\mathrm{mC}}\left[\beta_{\mathrm{mC}} \overline{\mathrm{k}}_{\mathrm{m}}+\beta_{\mathrm{fC}} \overline{\mathrm{k}}_{\mathrm{f}}\left(\frac{\mathrm{E}_{\mathrm{f} 11}}{\mathrm{E}_{\mathrm{m} 11}}\right)\right]
$$

Under compressive loading, it is also possible that a UFC will fail by a combination of debonding and intralaminar shear (ref. 8). This condition is approximated by the expression

$$
s_{l 11 D}=a_{1} s_{l 12 S}+a_{2}
$$


where $\mathbf{S}_{\mathrm{mC}}$ is the matrix compressive strength, $\beta_{\mathrm{mC}}$ and $\beta_{\mathrm{fC}}$ are theory-experiment correlation factors analogous to those for $S_{l 11 T}, a_{1}$ and $a_{2}$ are empirical curve-fit parameters, and $S_{212 S}$ is the UFC intralaminar shear strength, which will be defined subsequently. The remaining variables have already been defined. Equation (3) is the modified rule of mixtures matrix-strength limited but equation (4) limits $\mathrm{s}_{211 \mathrm{C}}$ by a combination of constituent debonding and intralaminar shear strength. The original forms of these equations were proposed by Fried (refs. 5 and 8). The equations were modified in reference 1 to incorporate several of the desirable features delineated in the INTRODUCTION. Equation (4) evolved from the experimental work of reference 8 where it was discovered that the longitudinal compressive failure stress depends on the intralaminar shear strength. The curve-fit parameters $a_{1}$ and $a_{2}$ in equation (4) are evaluated as is described in references 1 and 8 . It is possible that they would remain the same for various filament but only one-matrix systems. Though it is suspected that this might be the case, these coefficients should be evaluated for each filament-matrix system for reliable predictions. The important point to be noted in equation (3) is that $\mathrm{S}_{l 11 \mathrm{C}}$ is very sensitive to $\beta_{\mathrm{fC}}$ since $\left(\mathrm{E}_{\mathrm{f11}} / \mathrm{E}_{\mathrm{m11}}\right) \gg>1$. The important point to be noted in equation (4) is that the various fabrication process effects are introduced through $\mathrm{S}_{212 \mathrm{~S}}$, which is defined subsequently. It is suggested as a conservative measure that $\mathrm{S}_{l 11 \mathrm{C}}$ be taken as the smaller of the two values computed from equations (3) and (4) or in equation form

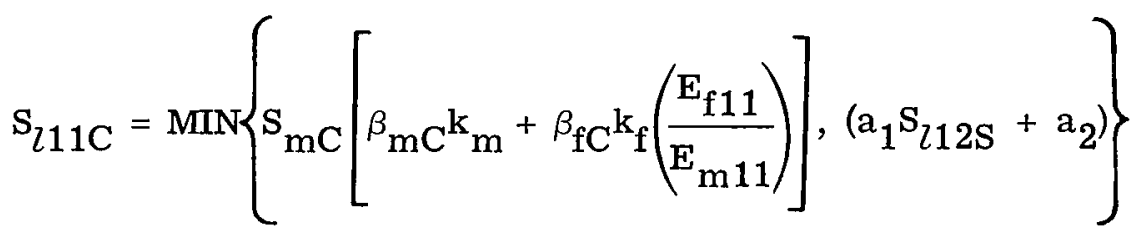

\section{Transverse Tensile Failure Stress $S_{222 T}$}

The governing equation for the transverse tensile strength is based on the hypothesis that $S_{222 T}$ is limited by the allowable tensile strain in the matrix (ref. 1, section 2.5). In equation form this condition is expressed by

$$
\mathrm{S}_{222 \mathrm{~T}}=f\left(\epsilon_{\mathrm{mpT}}\right) \mathrm{E}_{\ell 22}
$$

where $\epsilon_{\mathrm{mpT}}$ is the allowable matrix tensile strain defined in figure 2(a) (or any other suitable definition) and $\mathrm{E}_{222}$ is the composite transverse modulus. For the linear case, the following relation holds

$$
\mathrm{S}_{l 22 \mathrm{~T}}=\epsilon_{l 22 \mathrm{p}^{\mathrm{E}}} \mathrm{P}_{l 22}
$$




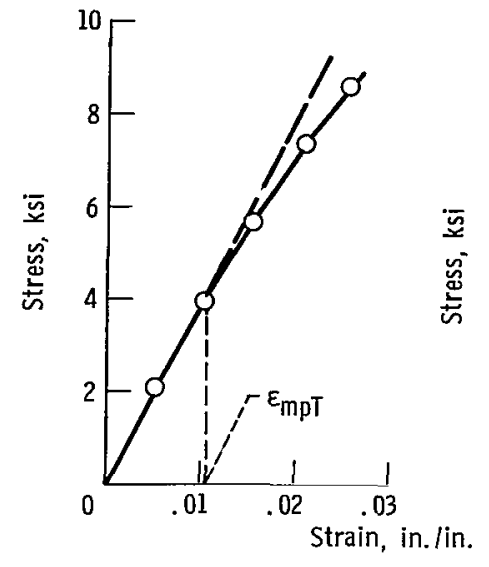

CS- 49308

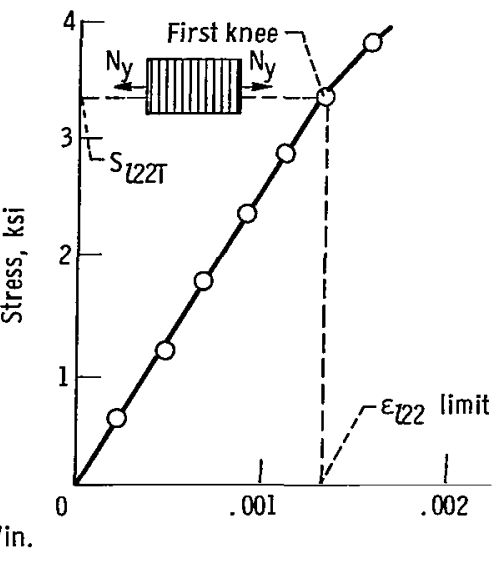

(b) Boron-epoxy composite.

Figure 2. Matrix and composite stress strain curves.

where $\epsilon_{222 p}$ is measured at the first knee (or point of linear deviation on the composite stress-strain curve as is illustrated in fig. 2(b)). (These data were obtained under Air Force contract AFML-TR-66-313.) It is shown in chapter 2 of reference 1 that the strains $\epsilon_{\mathrm{mpT}}$ and $\epsilon_{222 \mathrm{p}}$ are related by the following equation

$$
\epsilon_{222 p}=\beta_{22 \mathrm{~T}} \frac{\epsilon_{\mathrm{mpT}}}{\beta_{\mathrm{v}} \varphi_{\mu 22}}
$$

where $\beta_{22 \mathrm{~T}}$ is the theory-experiment correlation factor and $\beta_{\mathrm{v}}$ and $\varphi_{\mu 22}$ are the void effect and the matrix-strain-magnification factor, respectively, and are defined in the appendix. Substitution of equation (8) in equation (7) yields

$$
\mathrm{S}_{l 22 \mathrm{~T}}=\beta_{22 \mathrm{~T}} \frac{\epsilon_{\mathrm{mpT}}}{\beta_{\mathrm{v}} \varphi_{\mu 22}} \mathrm{E}_{\ell 22}
$$

Equation (9) relates $S_{222 T}$ to the limiting-matrix tensile strain, to the void effects, to the composite transverse modulus, and to the fabrication process through $\beta_{22 \mathrm{~T}}$. It is interesting to note that both local effects $\left(\beta_{v}\right.$ and $\left.\varphi_{\mu 22}\right)$ and average effects $\left(\mathrm{E}_{l 22}\right)$ influence the transyerse tensile strength. The coefficient $\beta_{22 \mathrm{~T}}$ should be selected so. that equation (9) correlates with experimental data. 


\section{Transverse Compressive Failure Stress $S_{222 C}$}

The governing equation for the transverse compressive strength is derived in a fashion similar to that used for $S_{222 \mathrm{~T}}$. The result is

$$
S_{222 C}=\beta_{22 C} \frac{\epsilon_{m p C}}{\beta_{v} \varphi_{\mu 22}}
$$

where $\beta_{22 \mathrm{C}}$ is the theory-experiment correlation factor, $\epsilon_{\mathrm{mpC}}$ is the limiting-matrix compressive strain, and the remaining variables are the same as for $\mathrm{S}_{l 22 \mathrm{~T}}$. It should be noted that equations (9) and (10) differ only in the correlation coefficients and the allowable matrix strains.

\section{Intralaminar Shear Failure Stress $S_{l 12 S}$}

The governing equation for the intralaminar shear strength is derived by a procedure similar to that used for $\mathrm{S}_{222 \mathrm{~T}}$. The result is

$$
\mathrm{S}_{212 \mathrm{~S}}=\beta_{12 \mathrm{~S}} \frac{\epsilon_{\mathrm{mpS}}}{\beta_{\mathrm{V}} \varphi_{\mu 12}} \mathrm{G}_{212}
$$

where $\beta_{12 \mathrm{~S}}$ is the theory-experiment correlation factor, $\epsilon_{\mathrm{mpS}}$ is the allowable matrix shear strain, $\mathrm{G}_{212}$ is the composite shear modulus, and $\beta_{\mathrm{v}}$ and $\varphi_{\mu 12}$ are the void ans shear matrix-strain-magnification factors and are defined in the appendix. The void effects are the same for $S_{l 22 \mathrm{~T}}, \mathrm{~S}_{l 22 \mathrm{C}}$, and $\mathrm{S}_{212 \mathrm{~S}}$ (ref. 1, ch. 2).

\section{Selection of the Correlation Coefficients for Simple Strengths}

The theory-experiment correlation coefficients in equations (2), (3), (9), (10), and (11) are selected from simple experimental setups as follows (see fig. 1): 


\begin{tabular}{|l|c|c|c|}
\hline \multirow{2}{*}{ Coefficient } & \multicolumn{3}{|c|}{ Stress } \\
\cline { 2 - 4 } & $\sigma_{211}$ & $\sigma_{222}$ & $\sigma_{212}$ \\
\hline$\beta_{\mathrm{fT}}, \beta_{\mathrm{mT}}$ & $\mathrm{S}_{211 \mathrm{~T}}$ & 0 & 0 \\
$\beta_{\mathrm{fC}}, \beta_{\mathrm{mC}}$ & $\mathrm{S}_{211 \mathrm{C}}$ & 0 & \\
$\beta_{22 \mathrm{~T}}$ & 0 & $\mathrm{~S}_{222 \mathrm{~T}}$ & \\
$\beta_{22 \mathrm{C}}$ & 0 & $\mathrm{~S}_{222 \mathrm{C}}$ & \\
$\beta_{12 \mathrm{~S}}$ & 0 & 0 & $\mathrm{~S}_{l 12 \mathrm{~S}}$ \\
\hline
\end{tabular}

It is recommended that $\beta_{12 \mathrm{~S}}$ be evaluated from thin tubular test specimens rather than short beam specimens since the uniform shear strength of a ply is required. A numerical example in selecting $\beta_{\mathrm{fT}}$ is illustrated in the appendix.

The important points to be noted in connection with equations (9) to (11) are that

(1) The failure stresses $S_{222 \mathrm{~T}}, \mathrm{~S}_{222 \mathrm{C}}$, and $\mathrm{S}_{212 \mathrm{~S}}$ are very sensitive to the matrix properties, to the composite elastic properties, to the void effects, and to the matrixstrain-magnification factor. Therefore, it is important that the matrix-strainmagnification factors be determined with sufficient accuracy.

(2) The nearness of the coefficients $\beta_{22 \mathrm{~T}}, \beta_{22 \mathrm{C}}$, and $\beta_{12 \mathrm{~S}}$ to unity is a measure of the validity of the hypothesis and of the insensitivity of the failure stresses $\mathrm{S}_{l 22 \mathrm{~T}}$, $\mathrm{S}_{222 \mathrm{C}}$, and $\mathrm{S}_{212 \mathrm{~S}}$ to the fabrication process.

It should be clear from the discussion to this point that all five UFC failure stresses, filament and matrix properties, filament and void content, matrix-strain-magnification factors and the UFC elastic properties are needed to evaluate the correlation coefficients Thus, the failure stress as well as filament and matrix properties and filament and void content should be made available by the material supplier. It cannot be overemphasized that these properties need to be known accurately for meaningful formulations of failure criteria and in particular for the selection of theory-experiment correlation factors. The matrix-strain-magnification factors and the UFC elastic properties can be computed when the constitutent material properties are known (appendix and refs. 1, 23, and 24).

The simple strengths of UFC from several filament matrix systems are available in the literature and are listed in table I. Three points should be noted in this table: (1) the simple strengths are for one filament volume content $\left(\mathrm{k}_{\mathrm{f}}\right)$; $(2)$ the simple strengths of the last four composites are preliminary data and may be modified as more published data become available; and (3) the magnitudes of the tensile and compressive strengths are considerably different. The correlation coefficients selected from the UFC simple strengths in table I are listed in table II. In table II many of the correlation coefficients are near unity. Some exceptions are the coefficients $\beta_{\mathrm{fC}}$ for all the composites and $\beta_{22 \mathrm{~T}}$ for some Thornel composites. The point to be noted is that the rule of mixtures 
TABLE I. - UNIDIRECTIONAL FILA MENTARY COMPOSITE

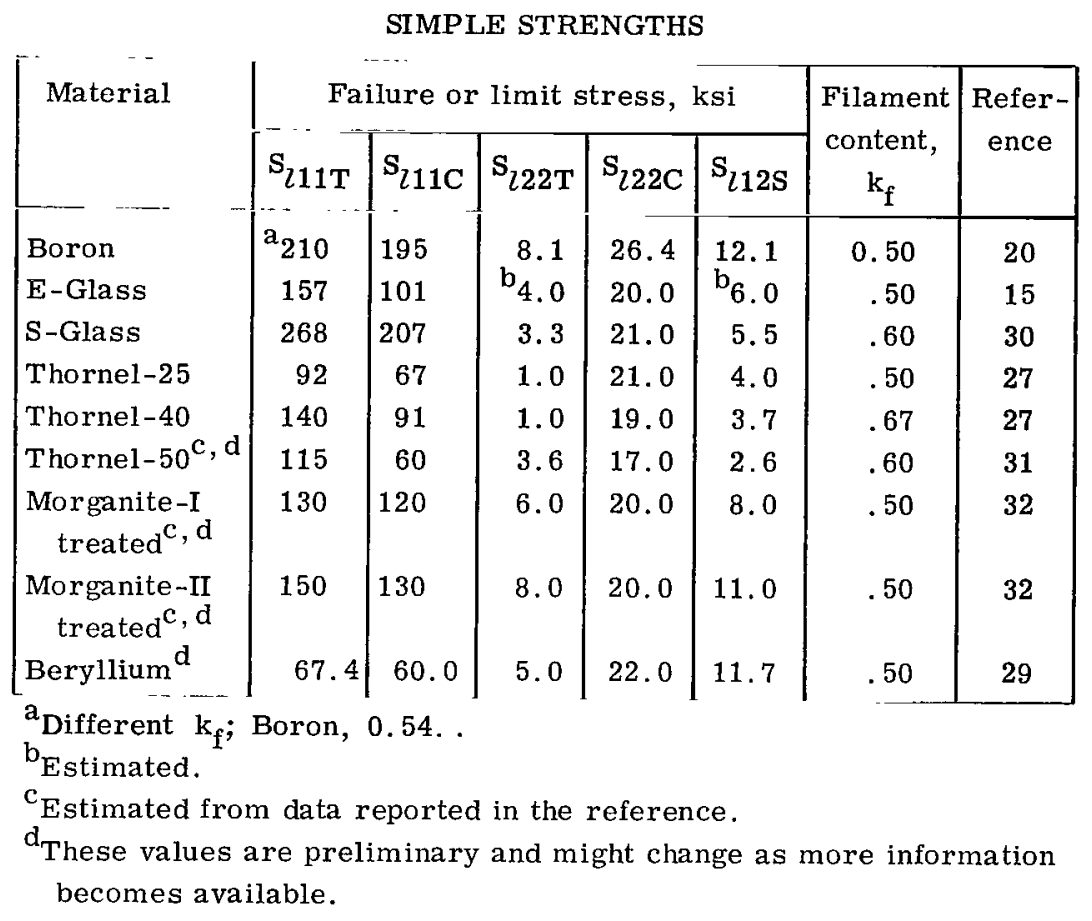

(matrix strength limited) is not a representative mechanistic model for $\mathrm{s}_{l 11 \mathrm{C}}$. The results of the Thornel composites indicate poor constituent bond, which behavior is similar to that of a large void content composite. The important point is that the equations derived here describe the UFC simple strength behavior satisfactorily. An additional important point concerning the first-level semiempirical theory is that the correlations coefficients in table II can be used to analyze, design, and develop failure envelopes for UFC of filament and void contents in the practical range $0.35 \lesssim \mathrm{k}_{\mathrm{f}} \lesssim 0.75$ and $0 \lesssim \mathrm{k}_{\mathrm{v}} \lesssim$ 0.20 . This should hold so long as the fabrication process variables noted in equation (1) remain invariant for that particular process. Of course, if any of these fabrication process variables change, then the coefficients need to be reevaluated.

The coefficients in the last four lines of table II are needed in the combined-stress strength criterion described in the next section. 
TABLE II. - CORRELA TION COEFFICIENTS FOR VARIOUS COMPOSITES

[ The $\beta$ coefficients correspond to data in table I.]

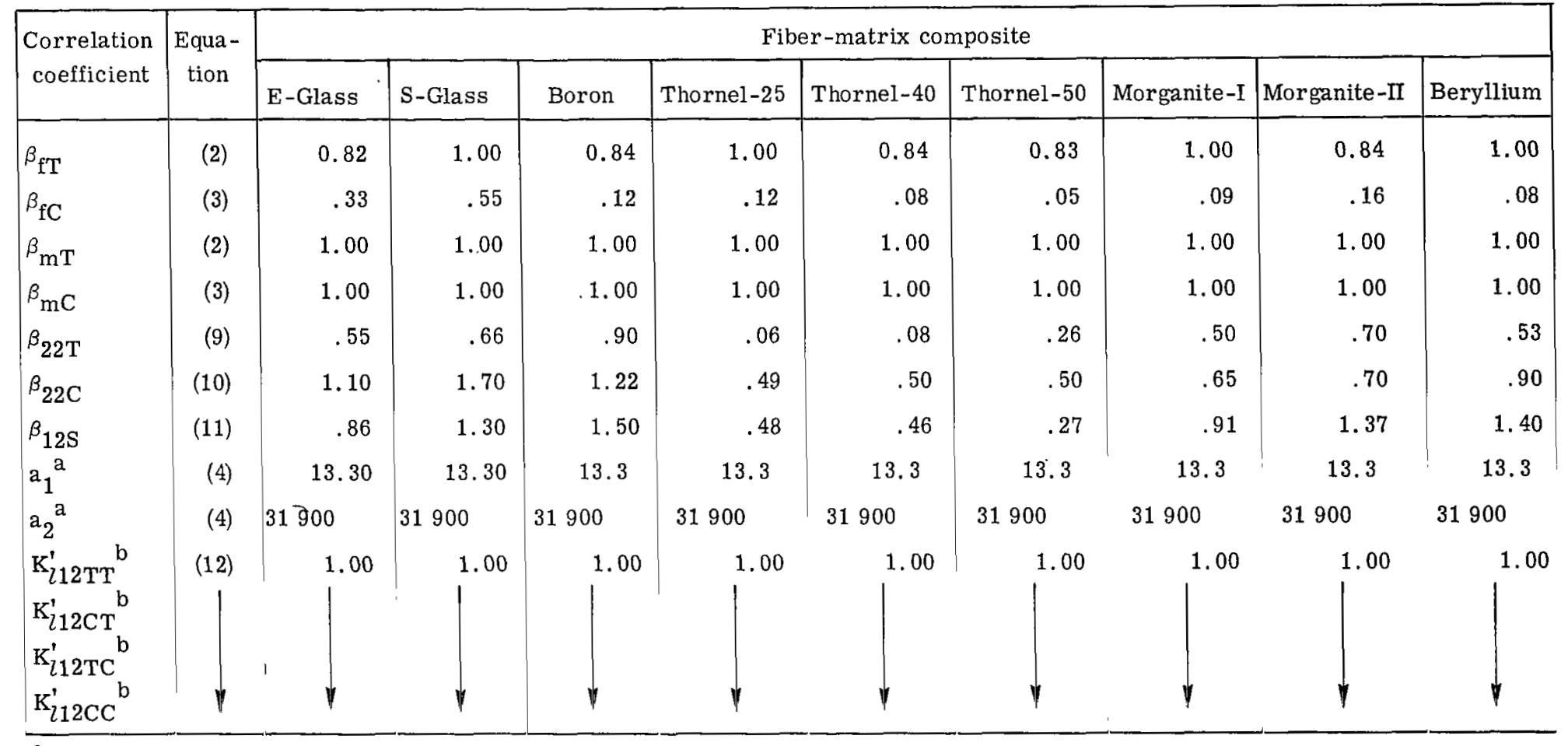

${ }^{a}$.For glass-epoxy composite; might need reevaluation for other composites.

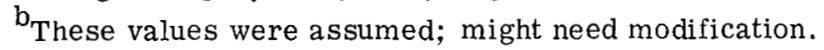




\section{COMBINED-STRESS STRENGTH CRITERION}

The governing equation for this criterion is derived from the following two postulates: (1) at the onset of failure, the distortion energy under simple and combined loading remains invariant, and (2) the tensile and compressive properties of UFC are the same up to the onset of failure. These two postulates are based on the von Mises criterion for isotropic materials and on the experimental observation that the distortion energy of UFC remains invariant under rotational transformation (ref. 1, section 3.3). The formal derivations are described in detail in section 3.3 of reference 1 . The resulting equation (from ref. 1) is

$$
\mathbf{F}\left(\sigma_{l}, \mathrm{~S}_{l}, \mathrm{~K}_{l 12}\right)=1-\left[\left(\frac{\sigma_{l 11 \alpha}}{\mathrm{S}_{l 11 \alpha}}\right)^{2}+\left(\frac{\sigma_{l 22 \beta}}{\mathrm{S}_{l 22 \beta}}\right)^{2}+\left(\frac{\sigma_{l 12 \mathrm{~S}}}{\mathrm{~S}_{l 12 \mathrm{~S}}}\right)^{2}-\mathrm{K}_{l 12 \alpha \beta} \mathrm{K}_{l 12} \frac{\sigma_{l 11 \alpha^{\sigma}}}{\left|\mathrm{S}_{l 11 \alpha}\right|\left|\mathrm{S}_{l 22 \beta}\right|}\right]
$$

where $F$ denotes the combined-stress strength criterion as follows:

$$
\begin{array}{ll}
\mathrm{F}\left(\sigma_{l}, \mathrm{~S}_{l}, \mathrm{~K}_{l 12}\right)>0 & \text { no failure } \\
\mathrm{F}\left(\sigma_{l}, \mathrm{~S}_{l}, \mathrm{~K}_{l 12}\right)=0 & \text { onset of failure } \\
\mathrm{F}\left(\sigma_{l}, \mathrm{~S}_{l}, \mathrm{~K}_{l 12}\right)<0 & \text { failure condition exceeded }
\end{array}
$$

and where subscripts $\alpha$ and $\beta$ denote $\mathrm{T}$ (tension) or $\mathrm{C}$ (compression), $\sigma_{2}$ denotes the applied stress state determined from the stress analysis, $\mathrm{S}_{l}$ denotes the UFC simple strength either determined from the equations described previously or measured exper imentally, and $\mathrm{K}_{212 \alpha \beta}^{\prime}$ is the theory-experiment correlation coefficient and is determined as will be described subsequently. The coefficient $\mathrm{K}_{l 12}$ is given by (from ref. 1 , ch. 3)

$$
\mathrm{K}_{l 12}=\frac{\left(1+4 \nu_{l 12}-\nu_{l 13}\right) \mathrm{E}_{l 22}+\left(1-\nu_{l 23}\right) \mathrm{E}_{l 11}}{\left[\mathrm{E}_{l 11} \mathrm{E}_{l 22}\left(2+\nu_{l 12}+\nu_{l 13}\right)\left(2+\nu_{l 21}+\nu_{l 23}\right)\right]^{1 / 2}}
$$

where $\mathrm{E}_{l}$ and $\nu_{l}$ denote UFC modulus and Poisson's ratio, respectively. The subscripts 11, 13, etc., refer to the corresponding axes in figure 1. For the case of isotropic material, equation (13) reduces to unity, as can be verified by direct substitution, and equation (12) reduces to the well known von Mises criterion. 
Several important points should be noted at this juncture: (1) The UFC do not exhibit similar properties in tension and compression, as was stated in the second postulate made at the beginning of this section. Therefore, $\mathrm{K}_{212 \alpha \beta}^{\prime}$ is introduced to compensate for this disparity. (2) Equation (12) describes failure at each quadrant by using, at most, four parameters. (3) The correlation coefficient $K_{l 12 \alpha \beta}^{\prime}$ can have different values in different quadrants. (4) The product $\mathrm{K}_{l 12 \alpha \beta}^{i} \mathrm{~K}_{l 12}$ can be defined as one constant and determined experimentally. However, this disguises the composite effects which are introduced into equation (12) through $K_{212}$. (5) The product $K_{l 12 \alpha \beta}^{\prime} K_{212}$ is not restricted to any range, that is, $-\infty<\mathrm{K}_{l 12 \alpha}^{\prime} \beta^{\mathrm{K}} \mathrm{K}_{212}<\infty$ (ref. 1, ch. 3). (6) Equation (12) is applicable to all materials exhibiting generally orthotropic elastic symmetry and is not restricted only to UFC.

Values of the variable $\mathrm{K}_{212}$ against $\mathrm{k}_{\mathrm{f}}$ are plotted in figure 3 for several filamentresin systems. The graphs in figure 3 are applicable to composites with various void

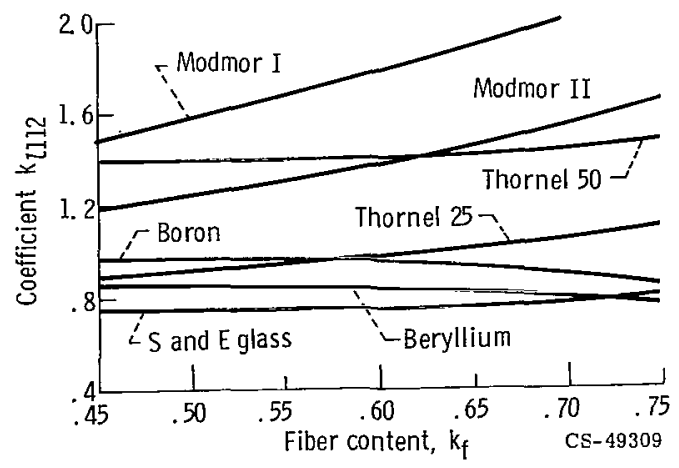

Figure 3. - Combined-stress strength-criterion coefficient (eq. (13)).

contents since $K_{l 12}$ is only slightly sensitive to the void content. A procedure to select the coefficients $K_{212 \alpha \beta}^{i}$ is illustrated in figure 4 . The experimental results in this figure are for JT-50 graphite at 10 percent porosity as reported in reference 21 . For this material $\mathrm{K}_{l 12}=0.85$. As can be seen from figure 4 , the coefficients $\mathrm{K}_{l 12 \alpha \beta}^{\prime}$ can be selected so that a good theory-experiment correlation can be obtained. One important point to be noted in figure 4 is that the slope of $\mathrm{F}\left(\sigma_{l}, \mathrm{~S}_{l}, \mathrm{~K}_{l 12}\right)$ is discontinuous across the quadrant junctures. This type of behavior is typical for orthotropic materials. Another important point is that the failure criterion is sensitive to $K_{212 \alpha \beta}^{\prime}$ in the tension-tension (TT) and compression-compression (CC) quadrants. 


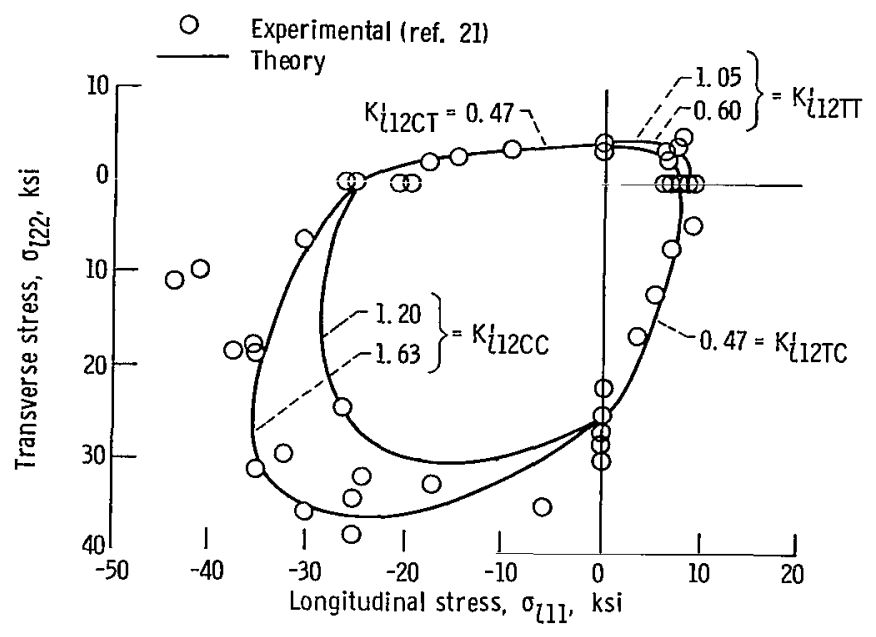

Figure 4. - Evaluation of correlation coefficient $K_{\lfloor, 120 \beta}$ (eq. (12)).

\section{APPLICATIONS, RESULTS, AND DISCUSSION}

The two-level semiempirical failure theory can be used in several ways: composite failure analysis, design, structural synthesis, generation of strength envelopes, and as an aid to experimental work. Here, the discussion is restricted to composite failure analysis (which serves as a verification of the two-level theory) and to the generation of strength envelopes (which points out problem areas in testing and design).

\section{Composite Failure Analysis and Theory Verification}

The two-level, semiempirical failure theory has been applied to several multilayered filament-matrix composites. The input data in these applications consisted of the constituent material properties, the filament and void contents, the correlation coefficients (table II), the composite geometry and the failure or maximum load. The generation of other required properties (ply elastic constants, simple strengths, etc.), the composite stress analysis, and the failure test according to equation (12) were carried out by a multilayered-filamentary-composite-analys is computer code (ref. 25). Typical results are presented in tables III to VI and described subsequently.

The results in table III are for Thornel-25 epoxy composite (for the narrow flat specimens reported in ref. 26). The first four columns in table III contain the composite geometry, the fifth column the applied load, and the last two columns the value of the failure criterion (eq. (12)) for the first and second plies. As can be seen in the last two columns of table III, the criterion predicts failure or nearly so in all composites except 
TABLE III. - RESULTS OF FAILURE ANA LYSES OF THORNEL-

25-EPOXY MULTILA YERED COMPOSITES BASED ON

NARROW SPECIMEN DATA FROM REFERENCE 26

\begin{tabular}{|c|c|c|c|c|c|}
\hline \multirow[t]{2}{*}{$\begin{array}{l}\text { Composite } \\
\text { ply } \\
\text { arrangement }\end{array}$} & \multirow[t]{2}{*}{$\begin{array}{c}\text { Fiber } \\
\text { content, } \\
\mathbf{k}_{\mathbf{f}}\end{array}$} & \multirow[t]{2}{*}{$\begin{array}{c}\text { Ply } \\
\text { thickness, } \\
t_{l}, \\
\text { in. }\end{array}$} & \multirow[t]{2}{*}{$\begin{array}{c}\text { Failure } \\
\text { load, } \\
\mathrm{N}_{\mathrm{x}}, \\
\text { lbf/in. }\end{array}$} & \multicolumn{2}{|c|}{$\begin{array}{c}\text { Failure criterion } \\
\text { (eq. (12)), } \\
\mathrm{F}\left(\sigma_{l}, \mathrm{~S}_{l}, \mathrm{~K}_{l 12}\right)\end{array}$} \\
\hline & & & & First ply & Second ply \\
\hline $9(0)$ & 0.324 & 0.0158 & 9270 & 0.16 & 0.16 \\
\hline $9(0,90)$ & .524 & .0136 & 2990 & .85 & -1.25 \\
\hline $9(90,0)$ & .557 & .0131 & 3650 & -2.87 & .52 \\
\hline $9( \pm 45)$ & .592 & .0127 & 876 & $\sim .24$ & -.24 \\
\hline $9( \pm 45)$ & .607 & .0126 & 822 & -.12 & -.12 \\
\hline $4(0,90,90,0)$ & .507 & .0138 & 2170 & .49 & $a_{-41.6}$ \\
\hline $4(90,0,0,90)$ & .475 & .0142 & 1922 & $a_{-32.2}$ & .60 \\
\hline $3(0,90,0)$ & .538 & .0134 & 1726 & .69 & $a_{-28.7}$ \\
\hline $3(90,0,90)$ & .554 & .0131 & 753 & ${ }^{a}-16.9$ & .57 \\
\hline $3( \pm 45)$ & .428 & .0150 & $\mathrm{~b}_{189}$ & .45 & .61 \\
\hline
\end{tabular}

a Load transfer difficulties.

$b_{\text {No failure }}$

TABLE IV. - RESULTS OF FAILURE ANALYSES OF THORNEL-40-EPOXY

MULTILA YERED COMPOSITES BASED ON DATA FROM REFERENCE 27

\begin{tabular}{|c|c|c|c|c|c|c|}
\hline \multirow[t]{3}{*}{$\begin{array}{l}\text { Composite ply } \\
\text { arrangement }\end{array}$} & \multirow{3}{*}{$\begin{array}{c}\text { Fiber } \\
\text { content, } \\
\mathrm{k}_{\mathrm{f}}\end{array}$} & \multirow{3}{*}{$\begin{array}{c}\text { Ply } \\
\text { thickness, } \\
\mathrm{t}_{l}, \\
\text { in. }\end{array}$} & \multicolumn{2}{|c|}{$\begin{array}{l}\text { Failure load, } \\
\text { lbf/in. }\end{array}$} & \multirow{2}{*}{\multicolumn{2}{|c|}{$\begin{array}{c}\text { Failure criterion } \\
\qquad(\text { eq. }(12)) \\
F\left(\sigma_{l}, S_{l}, K_{l 12}\right)\end{array}$}} \\
\hline & & & \multirow{2}{*}{$\mathrm{N}_{\mathrm{x}}$} & \multirow{2}{*}{$\mathrm{N}_{\mathrm{y}}$} & & \\
\hline & & & & & $\begin{array}{l}\text { First ply or } \\
\text { first pair }\end{array}$ & $\begin{array}{l}\text { Second ply or } \\
\text { second pair }\end{array}$ \\
\hline \multirow[t]{4}{*}{$4(90,0,0,90)$} & 0.64 & 0.0086 & 1960 & 0 & $a_{-16.5}$ & 0.63 \\
\hline & & & 0 & 2300 & .49 & ${ }^{a}-23.1$ \\
\hline & & & -1520 & 0 & .97 & -.03 \\
\hline & & & 0 & -1750 & -.36 & .95 \\
\hline \multirow[t]{4}{*}{$4(90,10,-10,90)$} & 0.57 & 0.010 & 1440 & 0 & $\mathrm{a}_{-7.80}$ & 0.73 \\
\hline & & & 0 & 2240 & .57 & $a_{-17.0}$ \\
\hline & & & -1520 & 0 & .96 & .14 \\
\hline & & & 0 & -1960 & .25 & .88 \\
\hline \multirow[t]{4}{*}{$4(10,-10,-10,10)$} & 0.69 & 0.0079 & 2120 & 0. & $\mathrm{a}_{0.52}$ & 0.52 \\
\hline & & & 0 & 31.6 & .23 & .23 \\
\hline & & & -1710 & 0 & -2.18 & -2.18 \\
\hline & & & 0 & -15.5 & -.16 & -.16 \\
\hline \multirow[t]{3}{*}{$6(10,-10,45,-45,10,-10)$} & 0.56 & 0.0102 & 3300 & 0 & 0.30 & -0.67 \\
\hline & & & 0 & 428 & -4.80 & -.78 \\
\hline & & & -2940 & 0 & .65 & -1.09 \\
\hline
\end{tabular}

\footnotetext{
${ }^{a}$ Load transfer difficulties
} 
TABLE V. - RESULTS OF FAILURE ANALYSES OF E-GLASS-EPOXY COMPOSITES BASED ON LONG TUBULAR SPECIMEN DATA FROM REFERENCE 28

\begin{tabular}{|c|c|c|c|c|c|c|}
\hline \multirow[t]{2}{*}{ Cylinder ${ }^{\mathrm{a}}$} & \multirow[t]{2}{*}{$\begin{array}{l}\text { Composite ply } \\
\text { arrangement }\end{array}$} & \multirow[t]{2}{*}{$\begin{array}{c}\text { Fiber } \\
\text { content, } \\
\mathbf{k}_{\mathrm{f}}\end{array}$} & \multirow[t]{2}{*}{$\begin{array}{c}\text { Ply } \\
\text { thickness, } \\
t_{l}, \\
\text { in. }\end{array}$} & \multirow{2}{*}{$\begin{array}{l}\text { Failure } \\
\text { load, } \\
\mathrm{N}_{\mathrm{x}} \\
\text { lof } / \mathrm{in} .\end{array}$} & \multicolumn{2}{|c|}{$\begin{array}{c}\text { Failure criterion } \\
(\text { eq. (12)) } \\
F\left(\sigma_{l}, S_{l}, K_{l 12}\right)\end{array}$} \\
\hline & & & & & $+\theta$ or $-\theta$ & $90^{\circ}$ \\
\hline 4 & $12(45,-45,90,90, \ldots)$ & 0.632 & 0.00455 & -568 & -0.25 & 0.80 \\
\hline 5 & & .625 & .00461 & -597 & -.30 & .79 \\
\hline 6 & & .655 & .00372 & -496 & -.57 & .75 \\
\hline 7 & $12(67.5,-67.5,90,90, \ldots)$ & 0.663 & 0.00464 & -541 & -0.09 & 0.68 \\
\hline 8 & & .660 & .00450 & -491 & .06 & .72 \\
\hline 9 & & .694 & .00460 & -557 & -.32 & .61 \\
\hline 1 & $12(25,-25,90,90, \ldots)$ & 0.638 & 0.00459 & -700 & 0.19 & 0.83 \\
\hline 2 & & .650 & .00457 & -654 & .22 & .84 \\
\hline
\end{tabular}

${ }^{\mathrm{a}}$ Numbers refer to cylinders reported in table $\mathrm{III}$ of reference 28.

TABLE VI. - RESULTS OF FAILURE ANALYSES OF BERYLLIUM MULTILA YERED COMPOSITES BASED ON DATA

FROM REFERENCE 29

\begin{tabular}{|c|c|c|c|c|c|}
\hline \multirow[t]{2}{*}{$\begin{array}{l}\text { Composite ply } \\
\text { arrangement }\end{array}$} & \multirow[t]{2}{*}{$\begin{array}{c}\text { Fiber } \\
\text { content, } \\
\mathrm{k}_{\mathrm{f}}\end{array}$} & \multirow{2}{*}{$\begin{array}{c}\text { Ply } \\
\text { thickness, } \\
\mathrm{t}_{\mathrm{l}} . \\
\text { in. }\end{array}$} & \multirow{2}{*}{$\begin{array}{c}\text { Failure } \\
\text { load, } \\
\mathrm{N}_{\mathrm{x}}, \\
\text { lbf/in. }\end{array}$} & \multicolumn{2}{|c|}{$\begin{array}{c}\text { Failure criterion } \\
\text { (eq. (12)) } \\
\mathrm{F}\left(\sigma_{l}, \mathrm{~s}_{l}, \mathrm{~K}_{l 12}\right)\end{array}$} \\
\hline & & & & First ply & Second ply \\
\hline \multirow[t]{3}{*}{$6(0,90,0,0,90,0)$} & 0.443 & 0.00666 & 2693 & -0.04 & 0.06 \\
\hline & .475 & .00643 & 2844 & -.16 & .02 \\
\hline & .541 & .00602 & 3012 & -.10 & -.53 \\
\hline \multirow[t]{3}{*}{$6(0,90,0,0,90,0)$} & 0.443 & 0.00666 & -2565 & $\mathrm{a}_{0.23}$ & 0.99 \\
\hline & .475 & .00643 & -2732 & $a-.14$ & .99 \\
\hline & .541 & .00602 & -2997 & a. 31 & .99 \\
\hline \multirow[t]{2}{*}{$6(0,60,-60,-60,60,0)$} & 0.459 & 0.00654 & 1787 & 0.12 & 0.57 \\
\hline & .459 & .00654 & -1915 & a. 38 & .95 \\
\hline
\end{tabular}

${ }^{a}$ Based on estimated value for $s_{211 C}$. 
the last one which was not carried to failure. The large negative values of the criterion indicate primarily two possibilities: (1) Load was nonuniformly transferred from the outer to the inner plies. (2) The transverse plies failed at an early state of the loading process and the load was carried primarily by the longitudinal plies. No stress-strain graphs were recorded to identify this condition. The criterion values of the longitudinal plies are in accord with the second possibility. This is another important use of the semiempirical theory; that is, it points out problem areas which need be either remedied or avoided. The results presented in table IV are for Thornel-40-epoxy composites (flat specimens). The experimental data are reported in reference 27 . The criterion predicts failure (or nearly so) for all these composites. The explanation of the large negative criterion values in this table is the same as that for table III.

Results of a different type are presented in table V. The experimental results for these cases were used to evaluate buckling of E-glass-epoxy cylinders and are reported in table III of reference 28 (Cylinders 1, 2 and 4 to 9). The number of plies and the ply thicknesses were deduced from the data presented in this reference. Here, the combinedstress strength criterion is applied to determine possible ply failure at the reported buckling load. The results of the analysis indicate failure of the ply material for the $\pm 45^{\circ}$ plies in cylinders 4 to 6 (reported to have failed by buckling) and the $\pm 67.5^{\circ}$ plies in cylinders 7 to 9 (reported to have failed by buckling and material failure) and no material failure, but nearly so, for the $\pm 25^{\circ}$ plies in cylinders 1 and 2 (reported to have failed by buckling). The results of the analysis of these cases further illustrate the usefulness of the criterion proposed herein in interpreting experimental results and also the failure mode complexities of angle ply composites.

Results of analyses for beryllium-epoxy composites (flat specimens) are presented in table VI. The experimental data for these composites were reported in reference 29. The ply-thickness simple strengths and the failure load (failure stress only reported) were deduced from the data presented in reference 29. The criterion predicts failure for the tensile load cases but for only one of the compressive load cases. This is because of the difficulty encountered in establishing a reasonable longitudinal compressive failure stress $S_{l 11 C}$ from the data reported in reference 29.

The results presented in tables III to VI tend to substantiate the two-level theory proposed here. And what is more important, they illustrate a relatively simple procedure to predict composite strength behaviors from basic constituent properties and fabrication process considerations.

\section{Generation of Strength Envelopes}

Envelopes for simple strengths and for the combined-stress strength criterion are presented in this section. Envelopes for unidirectional composites loaded with normal 


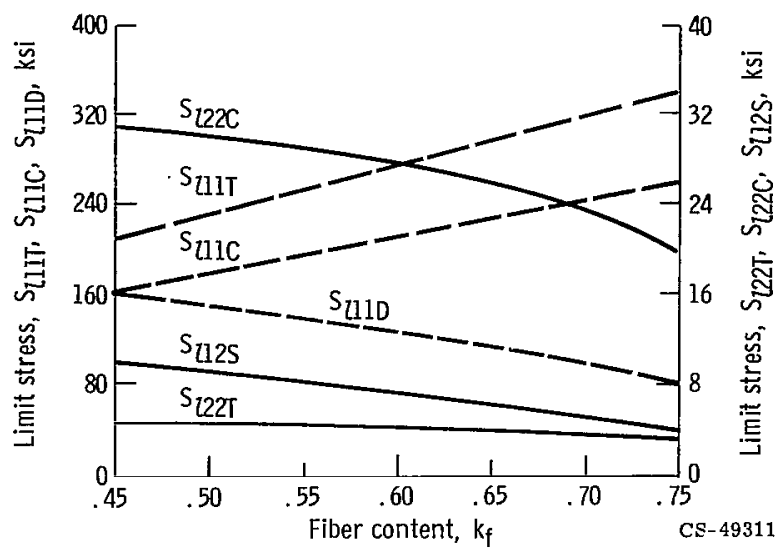

Figure 5. - Limit stress for S-glass-epoxy composites (based on correlation coefficients in table II and zero void content).

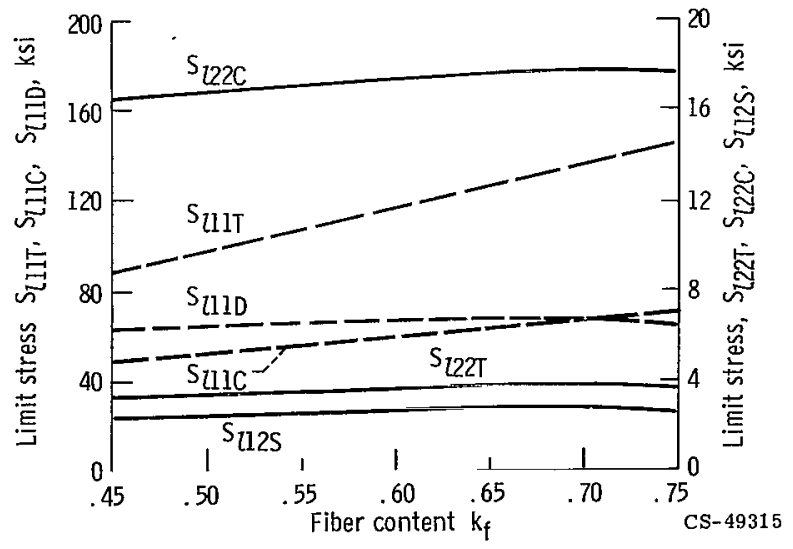

Figure 6. - Limit stresses for Thornel-50 - epoxy composites (based on correlation coefficients in table II and zero void content). 


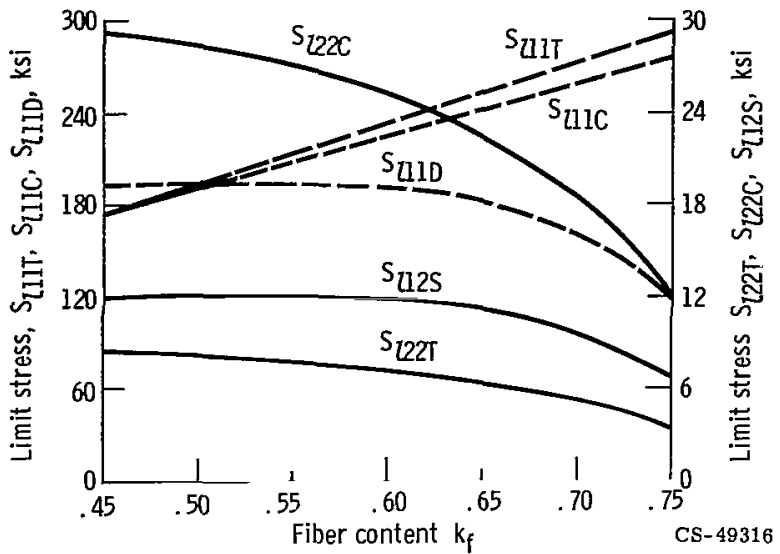

Figure 7. - Limit stresses for boron-epoxy composites (based on correlation coefficients in table II and zero void content).

and shear loads at some angle from the filament direction are also presented.

Figures 5 to 7 present graphs of the simple strengths $S_{211 T}, S_{211 C}, S_{211 D}$ (eq. (4)), $S_{l 22 T}, S_{l 22 C}, S_{l 12 S}$ against filament content $k_{f}$ with zero voids. These figures are, respectively, for S-glass, Thornel-50, and boron-filament UFC. The graphs in these figures were generated from the correlation coefficients in table $I$. The important points to be noted from these figures are that (1) the transverse and shear limit stresses decrease with increasing filament content for S-glass and boron composites but remain rather invariant for Thorne1-50 composites, (2) the decrease of these limit stresses $S_{l 22 T}$, $S_{l 22 C}$, and $S_{l 12 S}$ is very rapid for boron composites at high filament volume content values, and (3) test results for transverse and shear properties for isotropic filament composites should be reported with accurate volume content particularly in the high range. Those for or thotropic filaments $\left(E_{f 11} / E_{f 22}>>1\right)$ need not be very accurate. If longitudinal compressive failure of UFC is governed by $S_{l 11 D}$

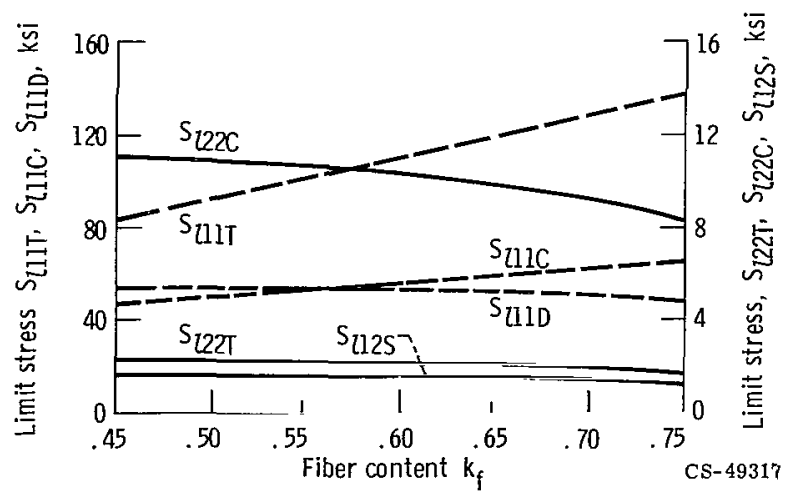

Figure 8. - Limit stresses for Thornel-50 - epoxy composites (based on correlation coefficients in table II and 5 percent void content). 
(constituent debonding and intralaminar shear), then this failure strength decreases with filament content $k_{f}$ (The value of $k_{f}$ should be measured fairly accurately).

Figures 8 and 9 present the simple strength envelopes for Thorne1-50 and boron composites with 5-percent void content, respectively. Superposition of figure 6 with 8 and figure 7 with 9 reveals a considerable drop in the transverse and shear strengths of composites with voids. It is important, therefore, to report the void content accurately when presenting experimental results on transverse and shear strengths. Of course the

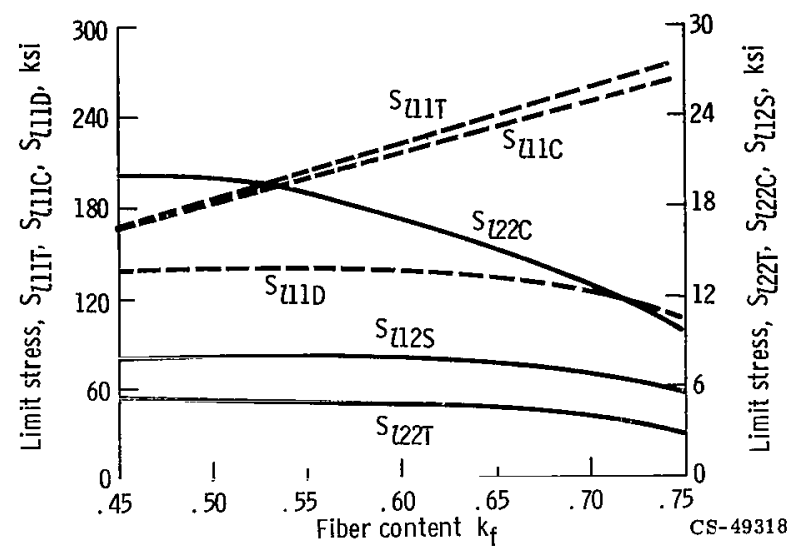

Figure 9. - Limit stresses for boron-epoxy composites (based on correlation coefficients in table II and 5 percent void content).

void content should be reported with longitudinal compressive strength as well since this strength could be governed by $S_{l 11 D}$ (constituent debonding and intralaminar shear).

The combined-stress strength behavior for a Thorne1-50 epoxy UFC is illustrated in figure 10. The contours in this figure represent strength envelopes for various values of

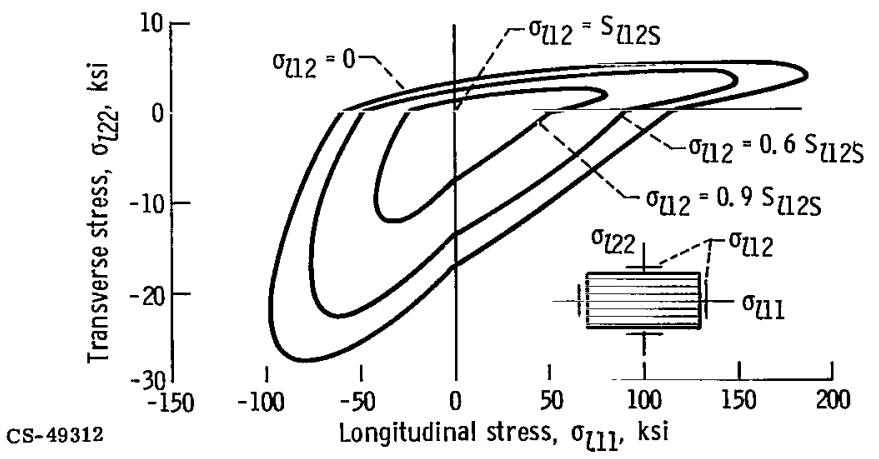

Figure 10. - Combined-stress strength-criterion for Thornel-50 epoxy composite (based on data in table I and eq. (12)). 
intralaminary shear expressed as a fraction of $s_{l 12 S}$. The three important points to be noted in figure 10 are that (1) Thornel-50 composites under the proper proportion of combined loading can resist considerably more load than their simple strengths would indicate, (2) the normal load capacity of this UFC is insensitive to small values of shear loads, and (3) the longitudinal compressive strength $\left(S_{211 C}\right)$ of UFC is very sensitive to transverse tensile loads while the longitudinal tensile strength is sensitive to transverse compressive loads and very sensitive to small transverse tensile stresses. Therefore, it is important to bear in mind (when testing for longitudinal strengths) that the trans verse stresses should be completely eliminated. A small amount of shear stress can be tolerated.

Figure 11 illustrates the strength envelope of UFC when loaded with normal loads at some angle to the filament direction. The upper part of the figure is for tensile load and the lower for compressive. These envelopes were obtained by expressing $\sigma_{l}$ in equa-

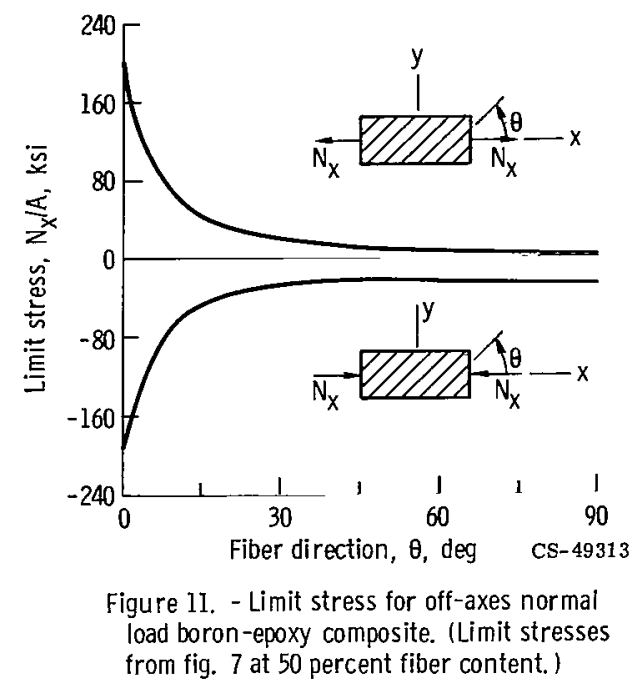

tion (12) in terms of $\sigma_{x}$ and then solving the resulting expression for $\sigma_{x}$. As can be seen in this figure, the strength drops off very rapidly. The composite has lost about 50 percent of its strength when the load is applied $5^{\circ}$ to the filament direction. It is imperative, therefore, to have the load completely alined with the filament direction for longitudinal tensile strength tests. In tests to determine strengths for $\theta>40^{\circ}$ (also transverse strength $\theta=90^{\circ}$ ) the load alinement is not critical.

Figure 12 illustrates an analogous effect for the case of shear load. Both positive (tending to elongate the filaments) and negative shear curves are shown in the figure. One important effect brought out by the negative shear curve (not widely recognized) is that UFC loaded with negative shear load $45^{\circ}$ to the filament direction has a very low 


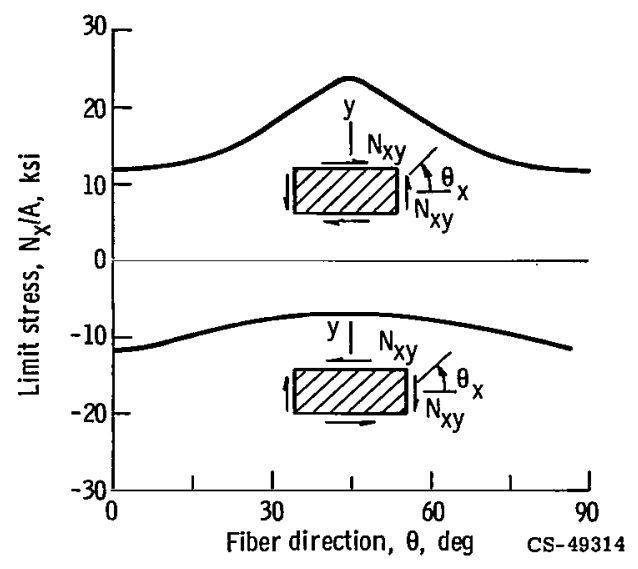

Figure 12. - Limit stress for off-axes shear load boron-epoxy composite. (Limit stresses from fig. 7 at 50 percent fiber content.)

shear strength. This means that, if $\pm 45^{\circ}$ plies are introduced to help carry shear loads, the $-45^{\circ}$ ply fails (perhaps not completely) at relatively small loads and the $\pm 45^{\circ}$ ply carries the load. The partially failed $-45^{\circ}$ ply causes the composite to exhibit a nonlinear load response as the loading increases. Other important points to be kept in mind for shear strength tests and design are that (1) the shear strength of UFC is insensitive to small angular deviations $(\theta \approx 0$ and $\theta \approx 90$ in fig. 12), (2) the strength of UFC loaded with positive shear load at $45^{\circ}$ is sensitive to small angular deviations, but it is insensitive if loaded with negative shear load, and (3) the strength of a UFC loaded with positive shear load at $45^{\circ}$ is approximately three times greater than the similar case with negative shear load. This ratio is approximately equal to $\mathrm{S}_{222 \mathrm{C}} / \mathrm{S}_{\ell 22 \mathrm{~T}}$.

Several recommendations have already been made on how theoretical work can aid the experimental effort. On the other hand, controlled experimental work is a very important asset in formulating and verifying any theory. For this reason, it is imperative that the complete test record (type of specimen, constituents, voids, type of test and techniques, type of failure, strain rate, means for measuring strain and elongation, and any other factors which influence the result) be reported when presenting experimental data for filamentary composite properties.

\section{CONCLUSIONS}

A two-level, semiempirical theory was developed to predict the strength behavior of unidirectional filamentary composites (UFC) from constituent material properties and from fabrication process considerations. This two-level theory describes the strength behavior of several filament matrix composites reasonably well. The two-level theory 
can be used to generate simple and combined strength envelopes for UFC.

The results of this investigation lead to the following conclusions:

1. The simple strengths are sensitive to the correlation coefficients and thereby to the particular fabrication process.

2. The simple strengths are fairly sensitive to void content.

3. The transverse and shear strengths are decreasing functions of the filament content (particularly at the high range) for isotropic filament composites.

4. The combined-stress strength criterion is sensitive to its correlation coefficient in the tension-tension and compression-compression quadrants and relatively insensitive in the other two quadrants.

5. The longitudinal compressive strength is very sensitive to the presence of transverse tensile stress.

6. The longitudinal tensile strength is very sensitive to small transverse compressive stress.

7. The normal load carrying capacity of a unidirectional filamentary composite decreases rapidly as the angle between filament and load direction increases. Consequently, the longitudinal tensile and compressive strengths are very sensitive to load misalinement.

8. The shear strength is insensitive to load misalinement.

9. The positive shear load carrying capacity of a unidirectional filamentary composite increases as the angle between filament and load direction increases to a maximum at $45^{\circ}$, but it decreases for negative shear load to a minimum at $45^{\circ}$.

10. Plies introduced to resist shear forces may do so by nonlinear response.

11. The complete test record should be reported when presenting experimental data on composite materials.

Lewis Research Center,

National Aeronautics and Space Administration,

Cleveland, Ohio, May 23, 1969, 124-08-06-01-22. 


\section{APPENDIX - USEFUL RELATIONS}

\section{Actual Filament and Matrix Volume Content}

Let $\mathrm{k}_{\mathrm{f}}$ and $\mathrm{k}_{\mathrm{m}}$ denote the apparent filament and matrix volume content, respectively, and let $\mathrm{k}_{\mathrm{v}}, \overline{\mathrm{k}}_{\mathrm{f}}$, and $\overline{\mathrm{k}}_{\mathrm{m}}$ denote the actual void, filament, and matrix volume content, respectively. Then it can be shown (ref. 1, appendix A) that

$$
\begin{gathered}
\overline{\mathrm{k}}_{\mathrm{f}}=\left(1-\mathrm{k}_{\mathrm{v}}\right) \mathrm{k}_{\mathrm{f}} \\
\overline{\mathrm{k}}_{\mathrm{m}}=\left(1-\mathrm{k}_{\mathrm{v}}\right)\left(1-\mathrm{k}_{\mathrm{f}}\right) \\
\mathrm{k}_{\mathrm{m}}=1-\mathrm{k}_{\mathrm{f}}
\end{gathered}
$$

\section{Matrix-Strain-Magnification Factors and Void Effects}

The transverse and shear matrix-strain-magnification factors are, respectively, given by (ref. 1, ch. 2):

$$
\varphi_{\mu 22}=\left[\frac{1}{1+\mathrm{p}(\overline{\mathrm{A}}=1)}\right]\left[1+\mathrm{p}\left(\nu_{\mathrm{f} 12}-\nu_{\left.\mathrm{m} 12^{\mathrm{A}}\right)}\left(\begin{array}{l}
\mathrm{E}_{l 22^{\sigma}} \sigma_{l 11}-\nu_{l 21} \mathrm{E}_{l 11} \sigma_{l 22} \\
\mathrm{E}_{l 11^{\sigma} \sigma_{l 22}}-\nu_{l 12} \mathrm{E}_{l 22} \sigma_{l 11}
\end{array}\right)\right]\right.
$$

if $\mathrm{E}_{l 11^{\sigma}}{ }_{\imath 22}-\nu_{\imath 12^{\mathrm{E}}}{ }_{\imath 11} \neq 0$

$$
\varphi_{\mu 22}=1
$$

and if $\mathrm{E}_{\imath 11^{\sigma}}{ }_{\imath 22}-\nu_{\imath 12} \mathrm{E}_{\imath 22^{\sigma}}{ }_{\ell 11}=0$

$$
\varphi_{\mu 12}=\frac{1}{1-p\left(1-\frac{G_{m 12}}{G_{f 12}}\right)}
$$

The maximum void effect factor is given by (ref. 1, ch. 2): 


$$
\beta_{\mathrm{v}}=\frac{1}{1-\left(\frac{4 \mathrm{k}_{\mathrm{v}}}{\pi \mathrm{k}_{\mathrm{m}}}\right)^{1 / 2}}
$$

where

$$
\begin{gathered}
\mathrm{p}=\left(\frac{4 \overline{\mathrm{k}}_{\mathrm{f}}}{\pi}\right)^{1 / 2} \\
\overline{\mathrm{A}}=\frac{1-\nu_{\mathrm{f} 12} \nu_{\mathrm{f} 21}}{1-\nu_{\mathrm{m} 12} \nu_{\mathrm{m} 21}} \frac{\mathrm{E}_{\mathrm{m} 22}}{\mathrm{E}_{\mathrm{f} 22}}
\end{gathered}
$$

and E, G, $\nu$, and $\sigma$ denote longitudinal modulus, shear modulus, Poisson's ratio, and stress, respectively. The subscripts $\mathrm{v}, \mathrm{f}$, and $\mathrm{m}$ denote void, filament, and matrix, respectively, and the numerical subscripts correspond to the filament directions depicted in figure 1 . The variable $\mathrm{k}_{\mathrm{v}}$ is the void content, and $\overline{\mathrm{k}}_{\mathrm{f}}$ and $\mathrm{k}_{\mathrm{m}}$ are defined by equations (A1) and (A3), respectively.

\section{Evaluation of Correlation Coefficients for Simple Strengths}

Several ways can be used to evaluate the correlation coefficients. The simplest one is illustrated by the following example using Thornel-25 epoxy:

$$
\begin{gathered}
\mathrm{S}_{\mathrm{fT}}=180000 \\
\mathrm{~S}_{l 11 \mathrm{~T}}=92000 \mathrm{psi} \\
\overline{\mathrm{k}}_{\mathrm{f}}=0.50 \\
\overline{\mathrm{k}}_{\mathrm{m}}=0.5 \\
\mathrm{E}_{\mathrm{f} 11}=25 \times 10^{6} \mathrm{psi} \\
\mathrm{E}_{\mathrm{m} 11}=0.55 \times 10^{6} \mathrm{psi}
\end{gathered}
$$


Solving equation (2) for $\beta_{\mathbf{f T}}$ yields

$$
\beta_{\mathrm{fT}}=\frac{1}{\overline{\mathrm{k}}_{\mathrm{f}}}\left(\frac{\mathrm{S}_{\mathrm{l11T}}}{\mathrm{S}_{\mathrm{fT}}}-\beta_{\mathrm{m} T} \overline{\mathrm{k}}_{\mathrm{m}} \frac{\mathrm{E}_{\mathrm{m} 11}}{\mathrm{E}_{\mathrm{f} 11}}\right)
$$

Assuming $\beta_{\mathrm{mT}}=1.0$ and substituting the values for all the variables in equation (A10) yield $\beta_{\mathrm{fT}} \approx 1.0$. The remaining correlation coefficients can be evaluated in the same fashion. 


\section{REFERENCES}

1. Chamis, Christos C.: Design Analysis and Structural Synthesis of Multilayered Filamentary Composites. Ph. D. Thesis, Case Western Reserve Univ., 1967.

2. Shibley, Allen M.; Peritt, Harvey L.; and Eig, Merill: A Survey of Filament Winding: Materials, Design Criteria, Military Applications. PLASTEC Rep 10, Picatinny Arsenal, May 1962.

3. Rosen, B. Walter: Tensile Failure of Fibrous Composites. ALAA J., vol. 2, no. 11, Nov. 1964, pp.1985-1991.

4. Majerus, J. N.; and Ferriera, S. K.: Fracture and Reliability of Filament-Wound Chambers. Am. Soc. Civil Eng., Eng. Mech. Div., vol. 91, no. EMI, Feb. 1965, pp. 107-136.

5. Fried, N.; and Kaminetsky, J.: The Influence of Material Variables on the Compressive Properties of.Parallel Filament Reinforced Plastics. SPI 19th Annual Conference, Society of the Plastics Industry, 1964, Sec. 9-A.

6. Dow, N. F.; and Rosen, B. W.: Evaluations of Filament-Reinforced Composites for Aerospace Structural Applications. NASA CR-207, 1965.

7. Foye, R. L.: Compression Strength of Unidirectional Composites. Paper 66-143, AIAA, Jan. 1966.

8. Fried, N.: The Response of Orthogonal Filament-Wound Materials to Compressive Stress. SPI 20th Annual Conference, Society of the Plastics Industry, 1965, pp. 1-1-C to 8-1-C.

9. Greszczuk, L. B. : Effect of Voids on Strength Properties of Filamentary ComComposites. SPI 22nd Annual Conference, Society of the Plastics Indsutry, 1967, pp. 20-A. 1 to 20-A. 10.

10. Foye, R. L.: An Evaluation of Various Engineering Estimates of the Transverse Properties of Unidirectional Composites. Science of Advanced Materials and Process Engineering Series. Vol. 10. Western Periodicals Co., 1966, pp. G-31 to $\mathrm{G}-42$.

11. Schulz, J. C.: Maximum Stresses and Strains in the Resin of a Filament-Wound Structure. SPI 18th Annual Conference, Society of the Plastics Industry, 1963, sec. $7-\mathrm{D}$.

12. Tsai, Stephen W. ; Adams, Donald F.; and Doner, Douglas R. : Effect of Constituent Material Properties on the Strength of Fiber-Reinforced Composite Materials. Rep. U-3592, Aeronutronics (A FML-TR-66-190, AD-638922), Aug. 1966. 
13. Ho., J. Y. L.; and Anthony, F. M. : Statistical A spects of Failure - Application to Grade JTA Graphite Composite Material. Integrated Research on Carbon Com posite Materials, Part 2. Union Carbide Corp. (AFML-TR-66-310, pt. 2, DDC No. AD-827594), Dec. 1967, pp. 36-50.

14. Marin, J.: Theories of Strength for Combined Stresses and Nonisotropic Materials. J. Aeron. Sci., vol. 24, no. 4, Apr. 1957, pp. 265-268.

15. Hoffman, Oscar: The Brittle Strength of Orthotropic Materials. J. Composite Materials, vol. 1, no. 2, Apr. 1967, pp. 200-206.

16. Tarnopolskiy, Yuriy M.; and Skudra, Al'bert M. : Construction Strength and Deformation Properties of Fiber Glass Reinforced Plastics. Rep. FRDL-T-1875-66, TT-67-60676, Inst. of Modern Languages, Inc., Dec. 1966. (Available from DDC as AD-645948.)

17. Hill, Rodney: The Mathematical Theory of Plasticity. Clarendon Press, Oxford, 1950.

18. Griffith, J. E.; and Baldwin, W. M.: Failure Theories for Generally Orthotropic Materials. Developments in Theoretical and Applied Mechanics. Vol. 1, Plenum Press, 1962, pp. 410-420.

19. Tsai, S. W.: Strength Theories of Filamentary Structures. Fundamental Aspects of Fiber Reinforced Plastic Composites. R. T. Schwartz and H. S. Schwartz, eds., Interscience Publ., 1968, pp. 3-11.

20. Waddoups, M. E.: Characterization and Design of Composite Materials. Composite Materials Workshop. S. W. Tsai, J. C. Halpin and N. J. Pagano, eds., Technomic Publishing Co., Inc., 1967, pp. 254-308.

21. Weng, T. L.: Biaxial Fracture Strength and Mechanical Properties of GraphiteBase Refractory Composites. Paper 68-337, AIAA, Apr. 1968.

22. Wu, Edward M.; and Reuter, R. C., Jr.: Crack Extension in Fiberglass Reinforced Plastics. Rep. T \& A M-275, Illinois Univ., Feb. 1965. (Available from DDC as AD-613576.)

23. Chamis, C. C.; and Sendeckyj, G. P.: Critique on Theories Predicting Thermoelastic Properties of Fibrous Composites. J. Composite Mat., vol. 2, no. 3, July 1968, pp. 332-358.

24. Chamis, C. C.: Thermoelastic Properties of Unidirectional Filamentary Composites by a Semiempirical Micromechanics Theory. Science of Advanced Materials and Process Engineering. Vol. 14. Western Periodicals Co., 1968, paper I-4-5. 
25. Chamis, C. C.; and Delivuk, T.: Multilayered Filamentary Composite Analysis Computer Code-User's Manual. Rep. 26, Case Western Reserve Univ., 1968.

26. Wu, C. H.: Tensile Testing of Graphite Composite Materials. Rep. 19, Case Western Reserve Univ., 1968.

27. Blakslee, O. L.; Pallozzi, A. A.; Doig, W. A.; Spence, G. B.; and Hanley, D. P.: Fabrication, Testing, and Design Studies With "Thornel" Graphite-Fiber, EpoxyResin Composites. Science of Advanced Materials and Process Engineering. Vol. 12。Western Periodicals Co., 1967, Sec. A-6.

28. Card, Michael F.: Experiments to Determine the Strength of Filament-Wound Cylinders Loaded in Axial Compression. NASA TN D-3522, 1966.

29. Schwartz, H. S.; Schwartz, R. T.; and Mahieu, W.: Mechanical Behavior of Beryllium Wire Reinforced Plastic Composites. Science of Advanced Materials and Process Engineering. Vol. 10. Western Periodicals Co., 1966, pp. A-41 to A -55.

30. Noyes, J. V.; and Jones, B. H.: Analytical Design Procedures for the Strength and Elastic Properties of Multilayer Fibruous Composites. Paper 68-336, AIAA, Apr. 1968.

31. Hoggatt, J. T.; Burnside, J. Y.; and Bell, J. E.: Development of Processing Techniques for Carbon Composites in Missile Interstage Application. Rep。D2125559-4 Boeing Co. (A FML-TR-68-155, AD-839 857L), June 1968.

32. Anon.: New Products Data Sheet. Morganite Research and Development Limited. 